\title{
Anti-Cancer Drug Delivery Modeling in Nanomedicine with Combinatorial Image Analysis and Non-Linear Regression
}

\author{
SANJAY GOSWAMI ${ }^{1}$, KSHAMA DHOBALE ${ }^{2}$, RAVINDRA WAVHALE $^{2}$, BARNALI \\ GOSWAMI $^{3}$, and SHASHWAT BANERJEE ${ }^{2}$
}

\author{
${ }^{1}$ Jadavpur University \\ ${ }^{2}$ Maharashtra Institute of Medical Education and Research \\ ${ }^{3} \mathrm{MIT}-W P U$
}

January 6, 2021

\begin{abstract}
Purpose: The field of cancer nanomedicine has made significant progress, but its clinical translation is impeded by many challenges, such as the difficulty in analysing intracellular anticancer drug release by the nanocarriers due to the lack of suitable tools. Here, we propose the development of a combinatorial imaging and analysis technique to evaluate anticancer drug such as doxorubicin $\mathrm{HCl}$ (DOX) released by a nanocarrier inside the HCT116 colon cancer cells and its subsequent intracellular accumulation. Procedure: Fluorescent cell images were captured and subjected to combined image analysis and machine learning based procedures to assess and quantify the delivery and retention rate of DOX inside the cancer cells by multifunctional CNT-DOX-Fe3O4nanocarrier. Results: We show that DOX in HCT116 cells was higher for multifunctional CNT-DOX-Fe3O4nanocarrierthan free DOX, indicating efficient and steady release of DOX as well as superior retentive property of the nanocarrier. Initially $(1 \mathrm{~h}$ and $4 \mathrm{~h}$ ) the luminance intensity of DOX in the cell cytoplasm delivered by CNT-DOXFe3O4nanocarrier was $\sim 0.34$ times and $~ 0.42$ times lesser than that of free DOX delivered normally. However, at $24 \mathrm{~h}$ and $48 \mathrm{~h}$ post treatment the luminance intensity of DOX for CNT-DOX-Fe3O4nanocarrier was $\sim 1.98$ times and 1.92 times higher than that of free DOX. Furthermore, the luminance intensity of DOX for CNT-DOX-Fe3O4in the whole cell was $\sim 1.35$ times and $\sim 1.62$ times higher than that of free DOX at $24 \mathrm{~h}$ and $48 \mathrm{~h}$, respectively. Conclusions: The high-throughput nature of our image analysis workflow allowed us to automate the process of DOX retention analysis, and enabled us to devise machine learningbased modeling to predict the percentage of anticancer drug retention in cells. The development of models to automatically quantify and predict intra-cellular drug release in cancer cells could benefit personalized treatments by optimizing the design of nanocarriers.
\end{abstract}

\section{Hosted file}

Anti-Cancer Drug Delivery Modeling in Nanomedicine with Combinatorial Image Analysis and Non-Linear Reg available at https://authorea.com/users/387809/articles/502738-anti-cancer-drug-deliverymodeling-in-nanomedicine-with-combinatorial-image-analysis-and-non-linear-regression 

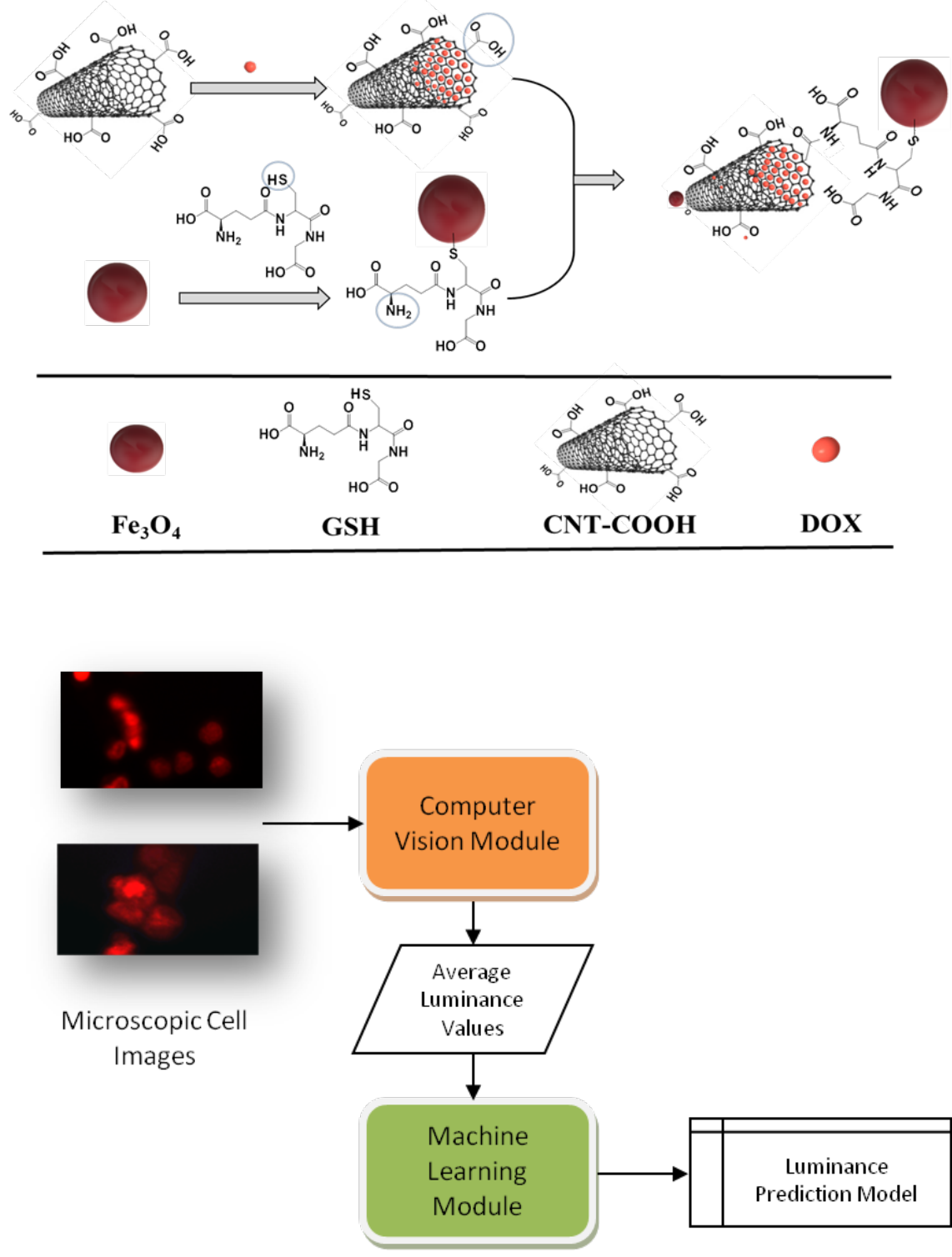


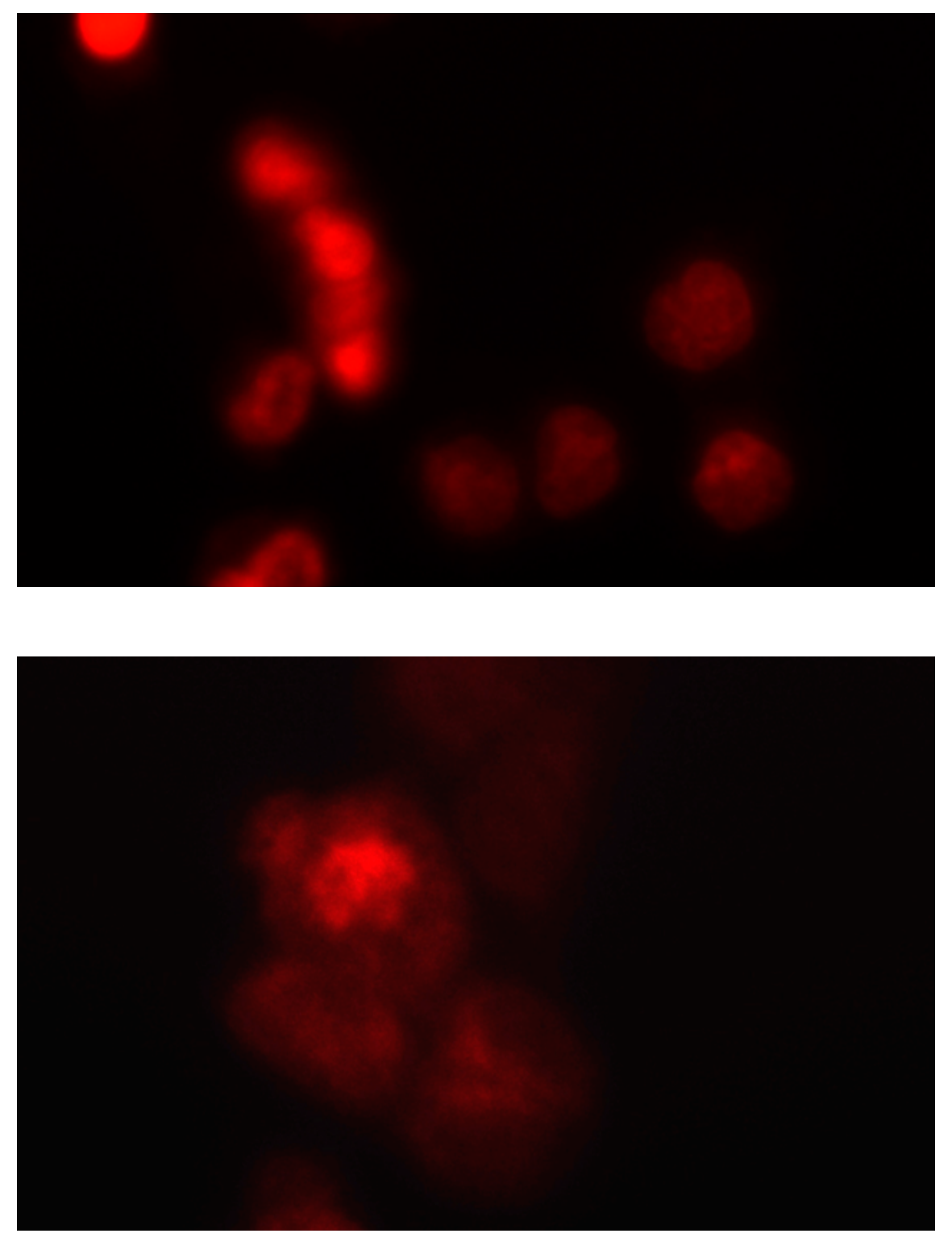




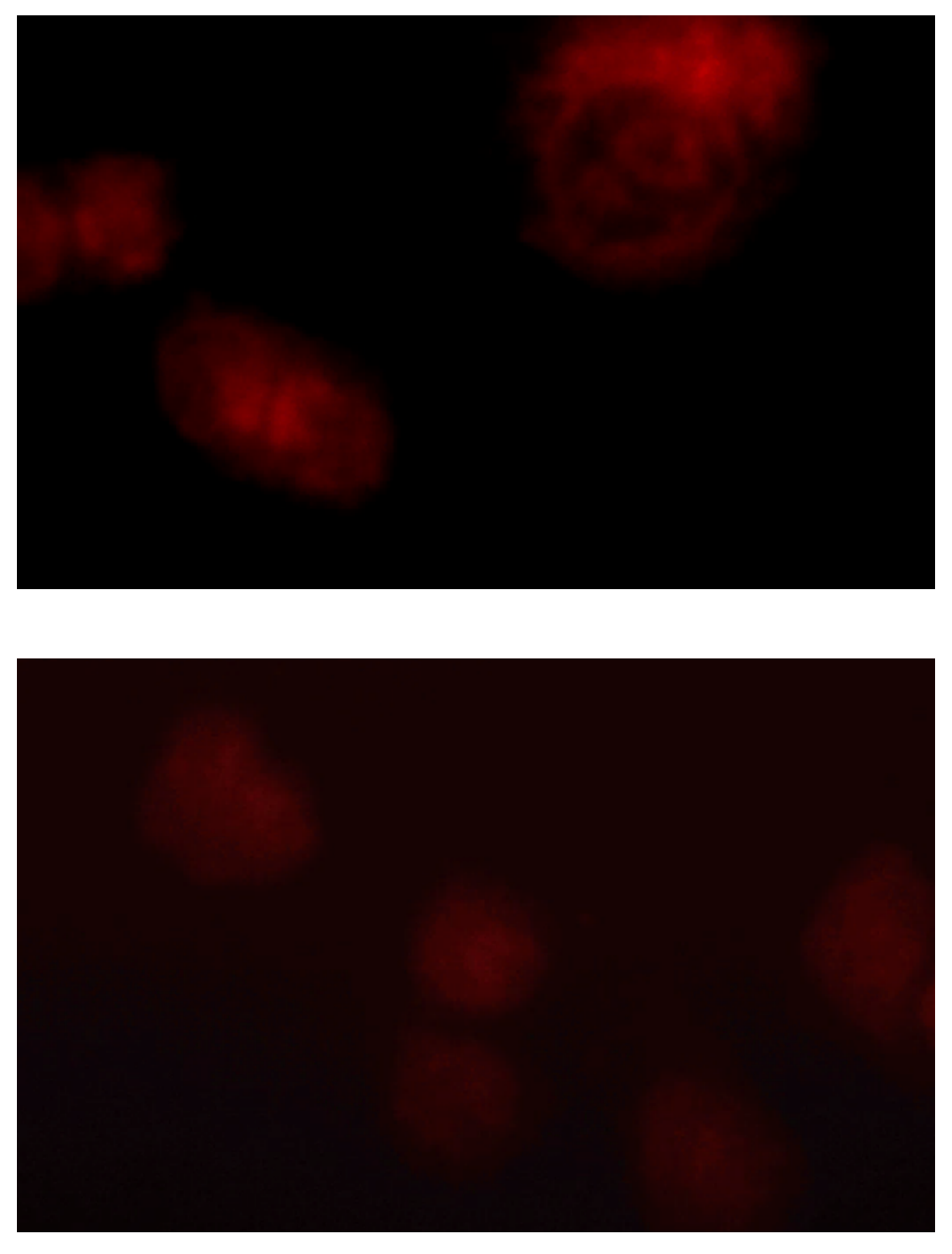



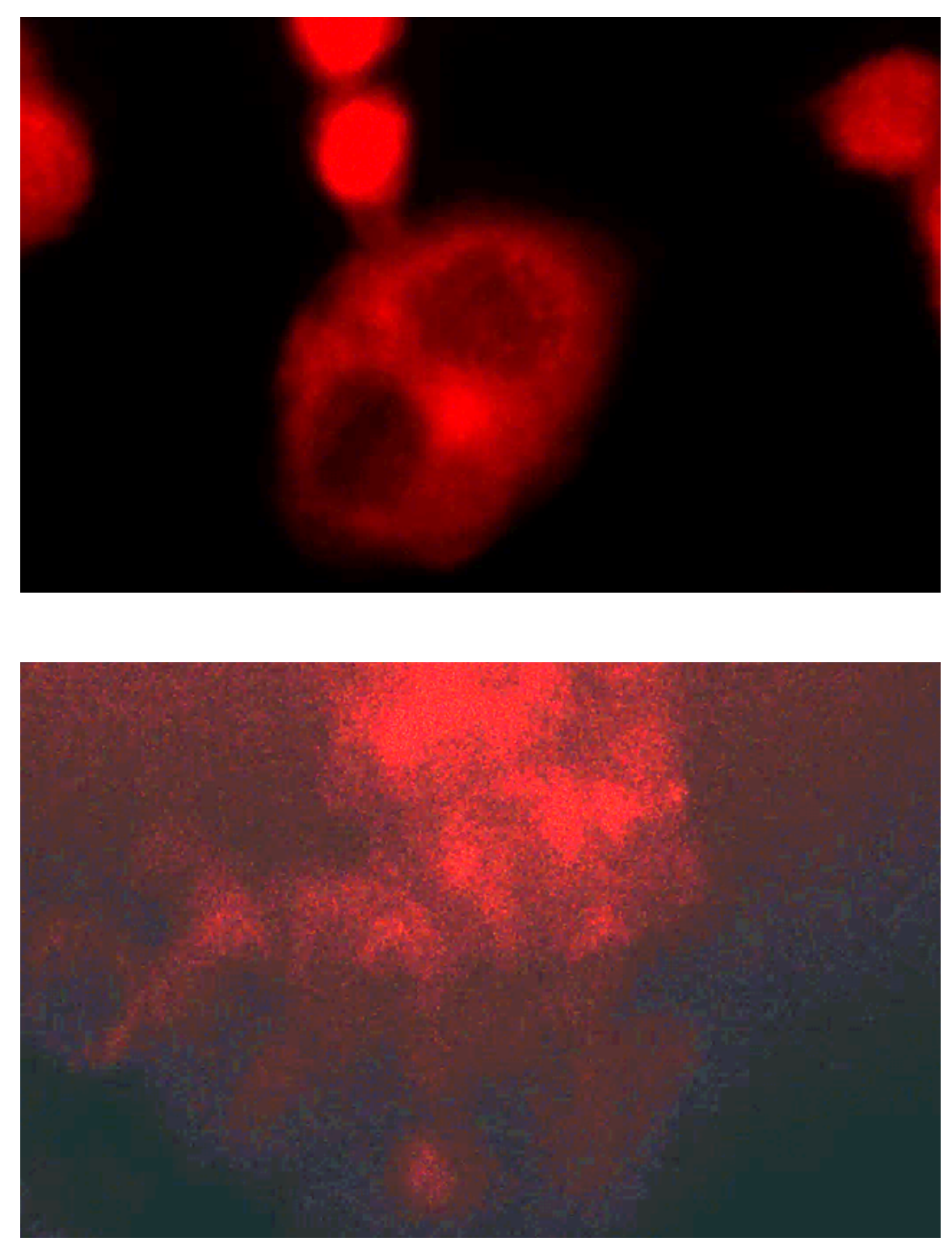


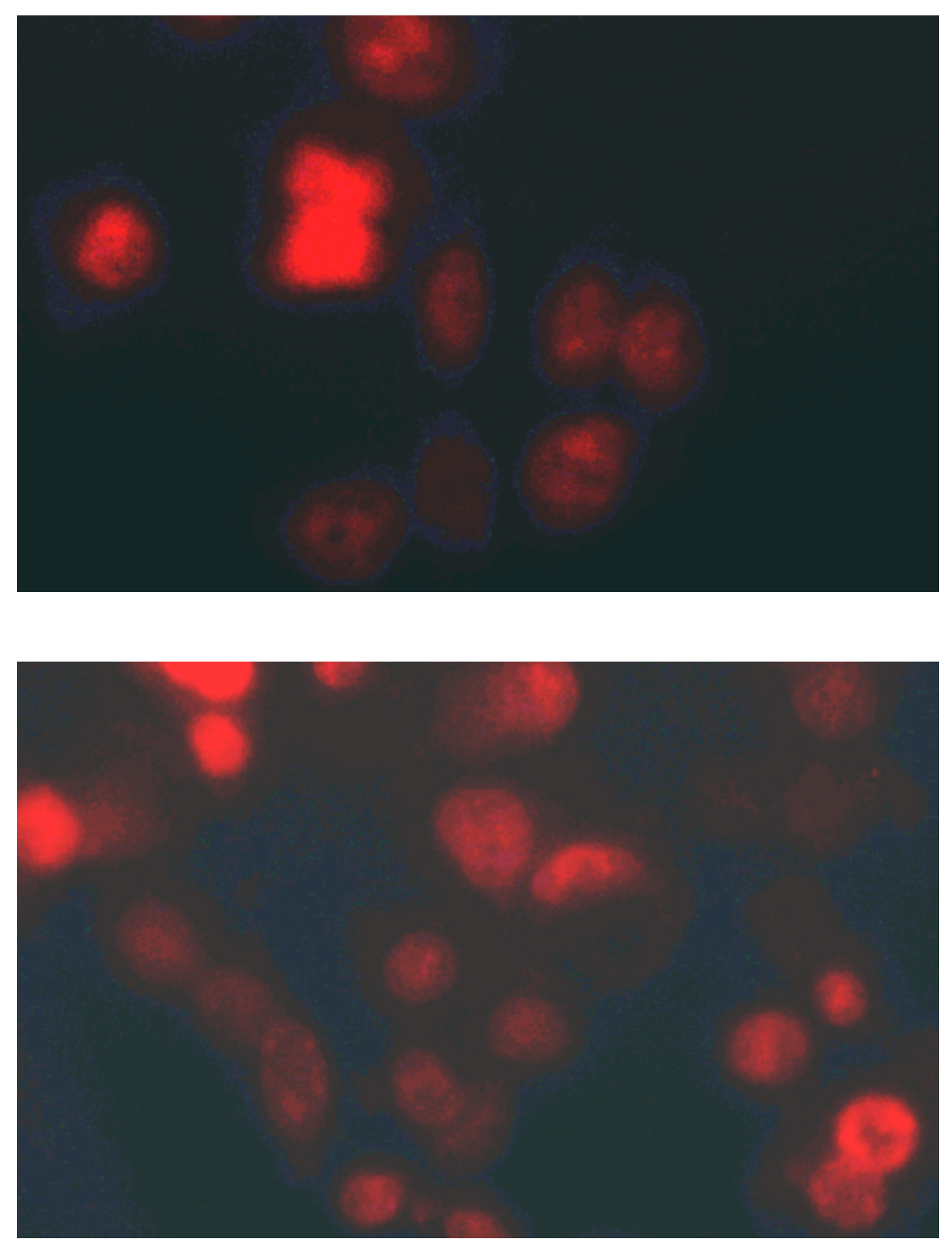



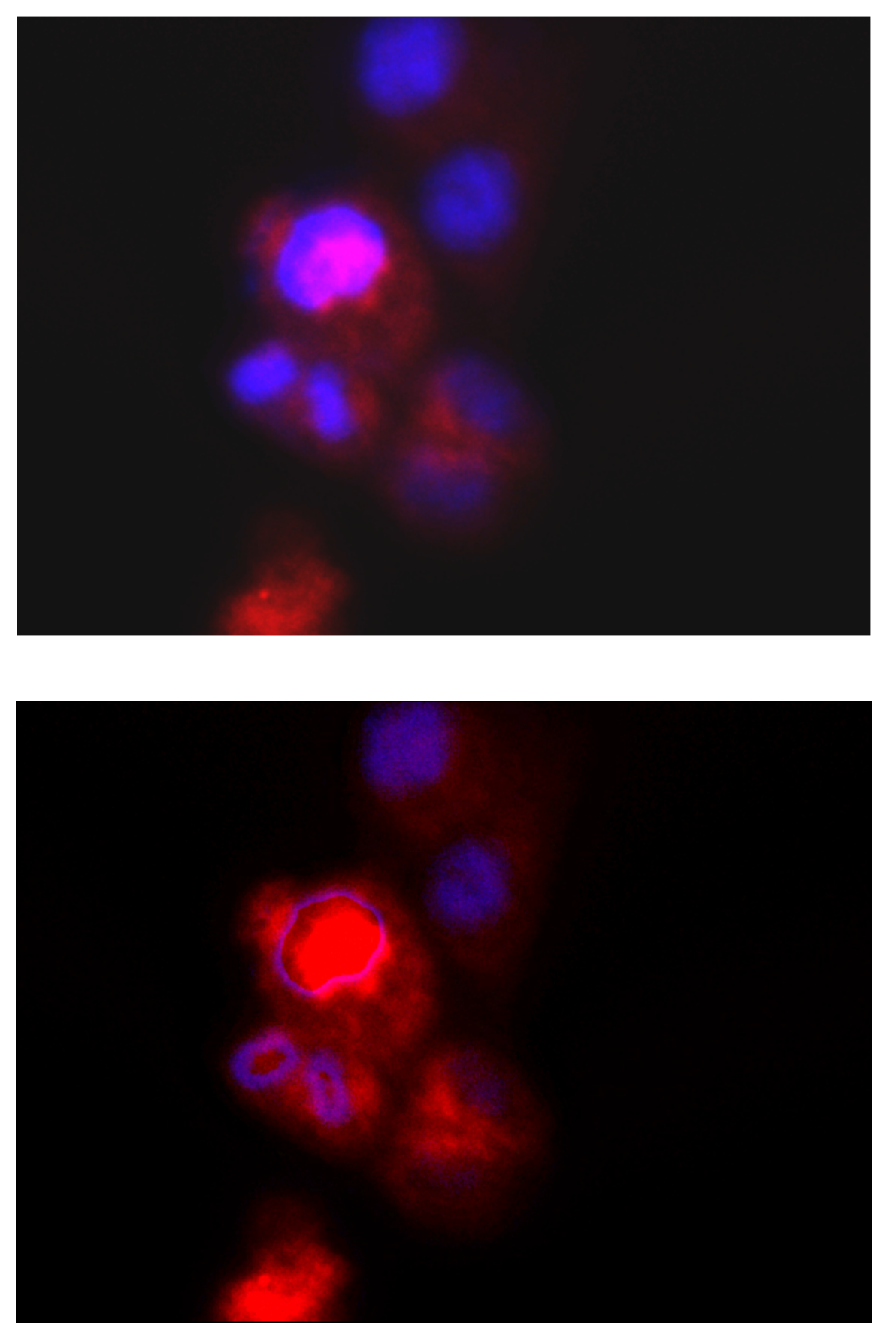


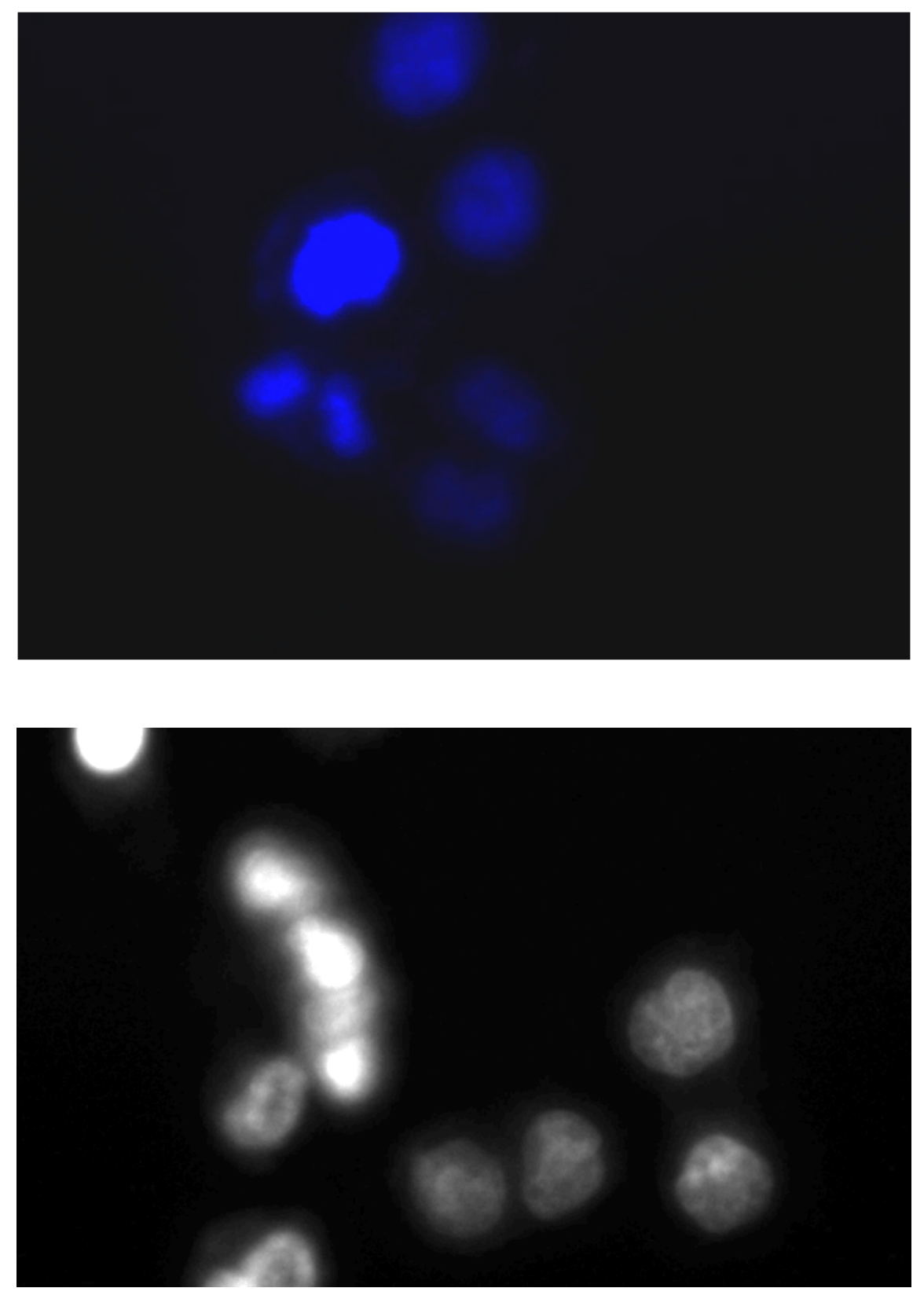


FREE DOX CELL LUMINANCE SCATTER PLOT

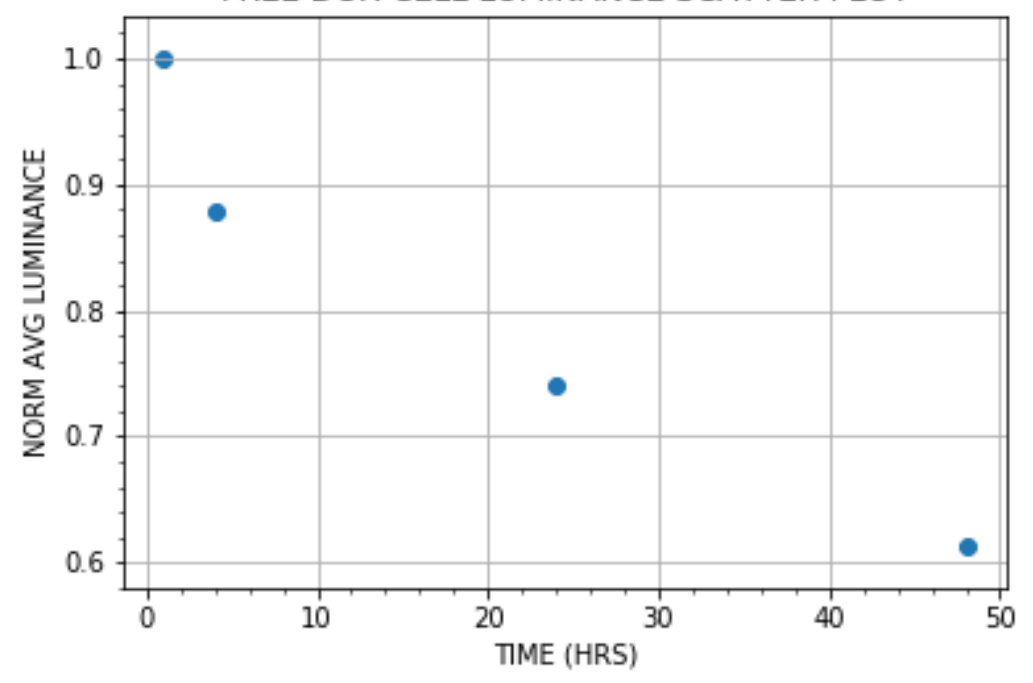


FREE DOX CYTO LUMINANCE SCATTER PLOT
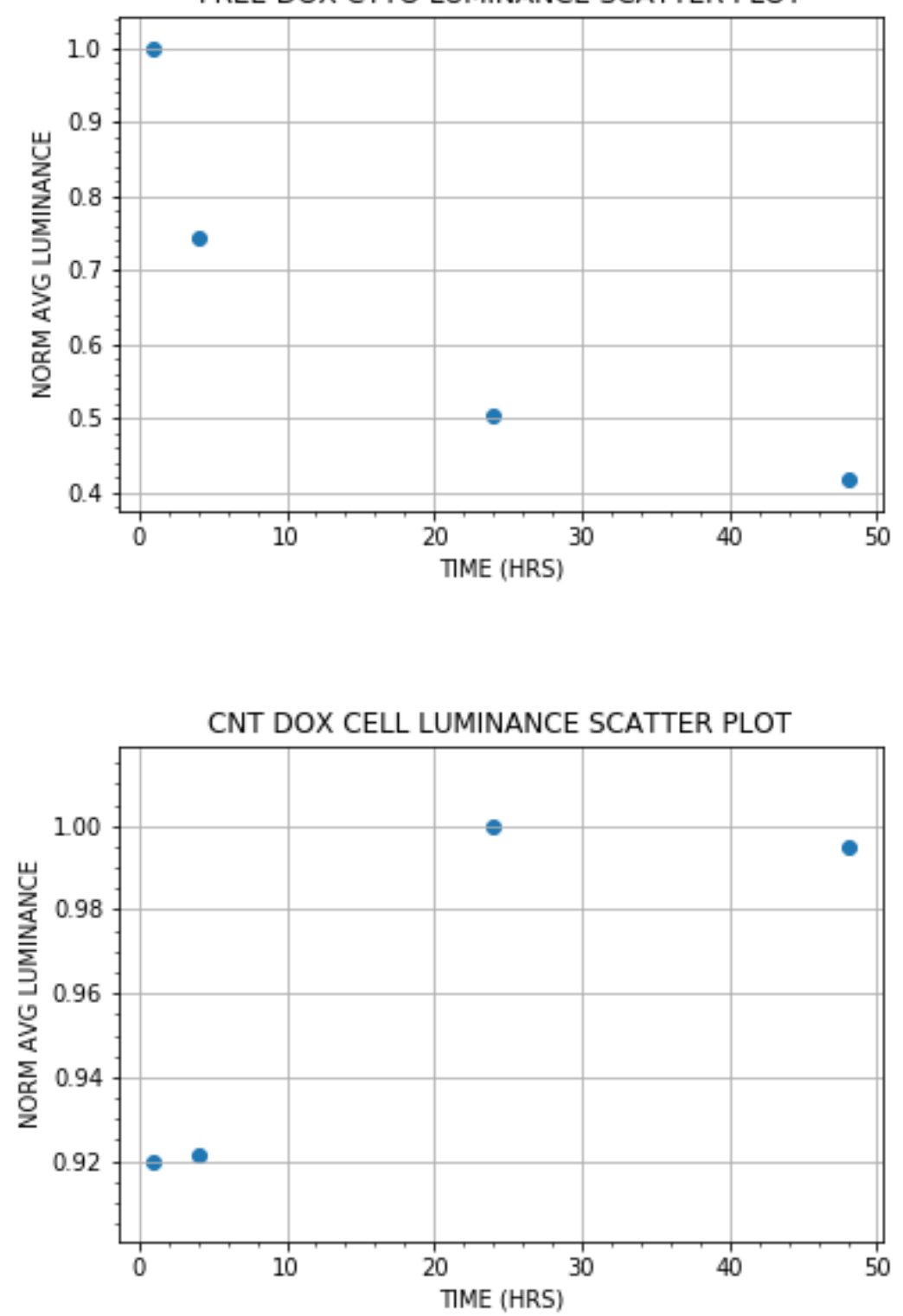

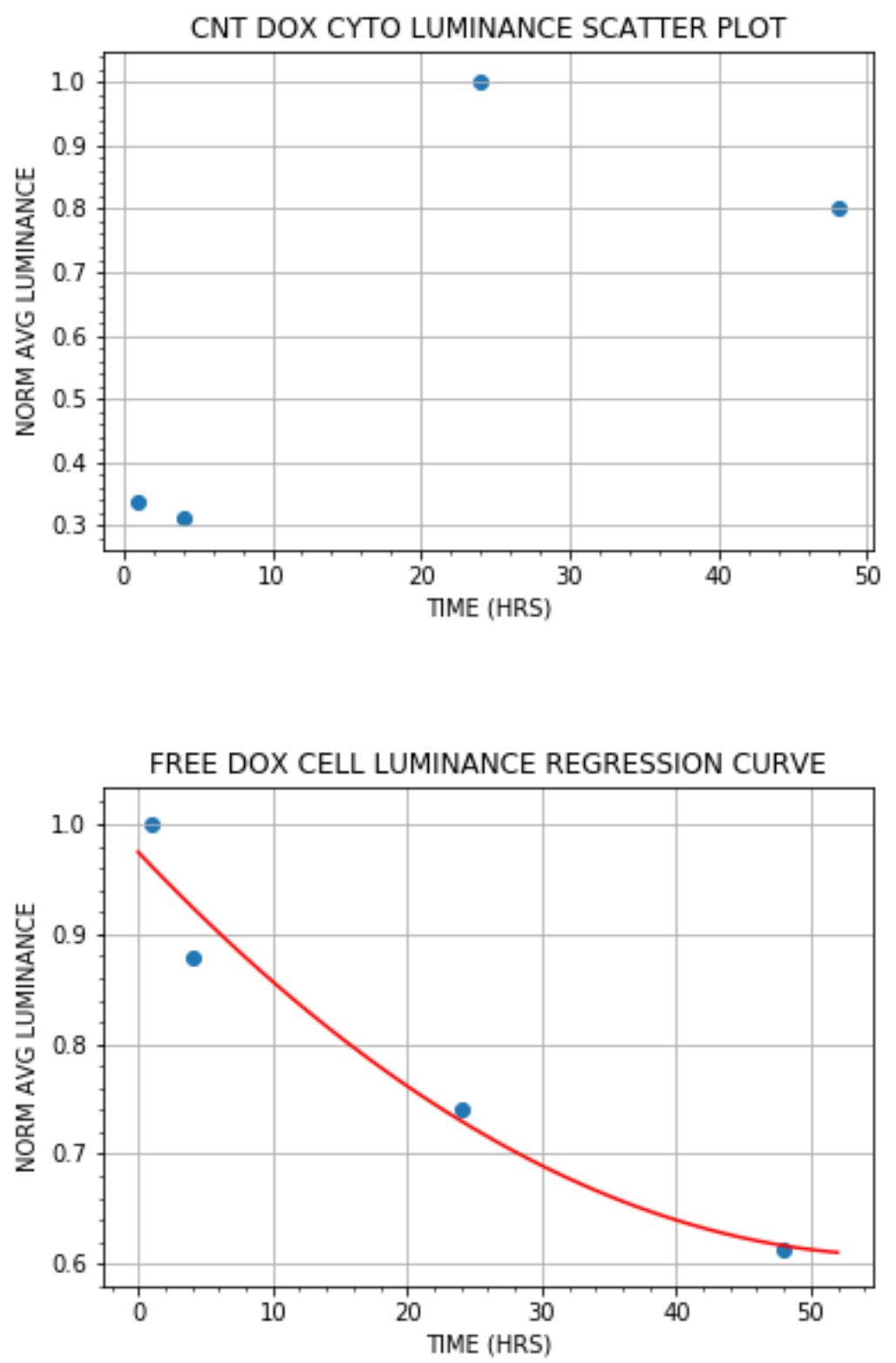
FREE DOX CYTO LUMINANCE REGRESSION CURVE
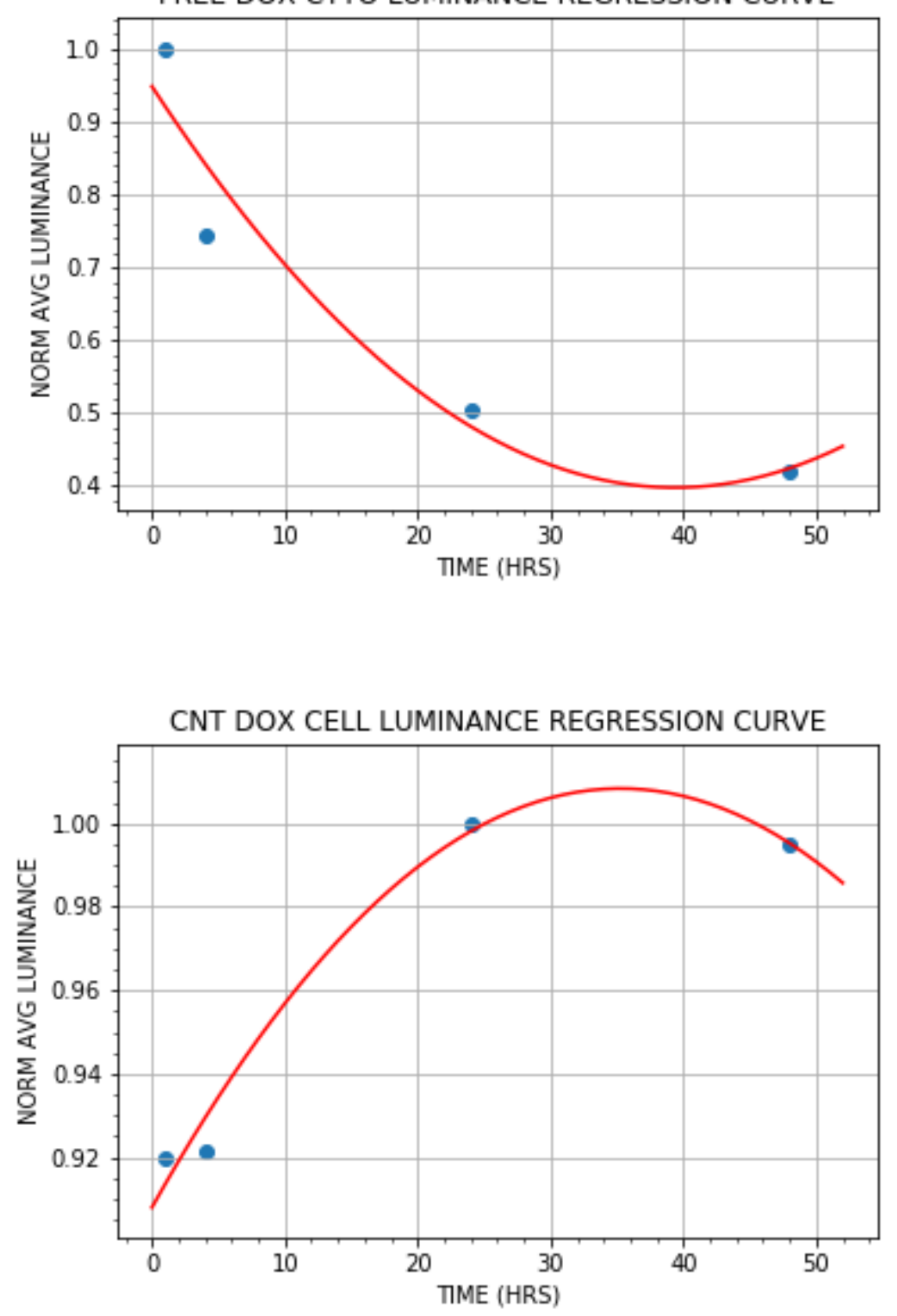


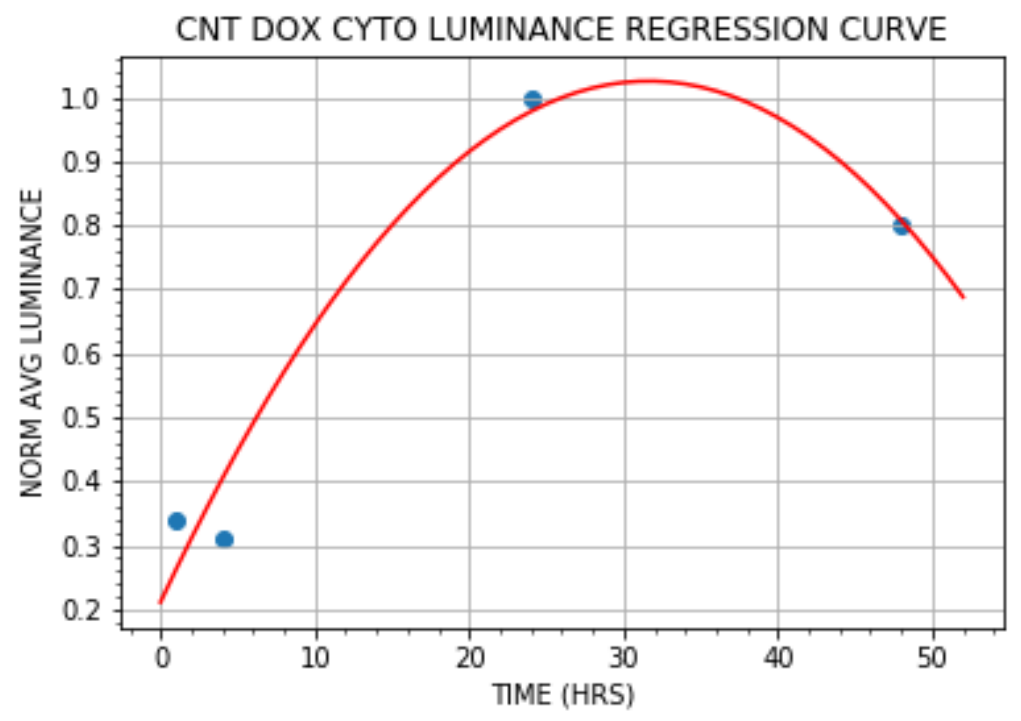

